\title{
Successful management of an orocutaneous fistula and exposed mandibular plate with the vacuum-assisted closure system: A case report
}

\author{
HIROYUKI GODA, TOMOHIRO HAMAKAWA and KOH-ICHI NAKASHIRO
}

Department of Oral and Maxillofacial Surgery, Ehime University Graduate School of Medicine, Toon, Ehime 791-0204, Japan

Received November 7, 2017; Accepted June 22, 2018

DOI: $10.3892 /$ etm.2018.6869

\begin{abstract}
Orocutaneous fistulas are one of the most problematic postoperative complications after oral cancer surgery. Notably, in patients with mandibular plate exposure it is necessary to remove the plate. However, it takes longer for these patients to achieve complete fistula closure. The present report described an 84-year-old man with a postoperative orocutaneous fistula and exposed mandibular plate who was treated with the vacuum-assisted closure system. This system protects the wound from contamination while the negative pressure prevents tissue fluid retention, promotes blood flow, facilitates granulation tissue formation and decreases the bacterial cell count. Vacuum-assisted closure was successful in the present case, and complete fistula closure took 20 days. Additionally, there was no evidence of recurrence over the 11-month follow-up.
\end{abstract}

\section{Case report}

An 84-year-old Japanese man with a T4aNOM0 squamous cell carcinoma of the left lower gingiva underwent left supraomohyoid neck dissection, left-sided segmental mandibulectomy, and pectoralis major myocutaneous flap with a titanium reconstruction plate. On postoperative day 9 , dehiscence of the pectoralis major myocutaneous flap from the floor of the mouth to the gingiva was noted. Saliva and pus could be expressed from the chin incision with palpation, and exposure of the titanium reconstruction plate and the presence of an orocutaneous fistula were confirmed (Fig. 1). The patient received antibiotics (flomoxef sodium, $2 \mathrm{~g} /$ day), and debridement was performed until healthy, bleeding tissues were reached. On postoperative day 14, the vacuum-assisted closure (VAC) system (VAC Therapy ${ }^{\mathrm{TM}}$; KCI Medical, Ltd.,

Correspondence to: Dr Hiroyuki Goda, Department of Oral and Maxillofacial Surgery, Ehime University Graduate School of Medicine, 454 Shitsukawa, Toon, Ehime 791-0204, Japan

E-mail: hiro9832@m.ehime-u.ac.jp

Key words: vacuum-assisted closure, mandibular plate exposure, orocutaneous fistula
Oxfordshire, United Kingdom) was applied to the wound. The wound was sealed with an adhesive drape, which covered the polyurethane foam (V.A.C. GranuFoam ${ }^{\mathrm{TM}}$, KCI Medical, Ltd.) and tubing, including $3 \mathrm{~cm}$ of the surrounding normal skin to ensure a complete seal. Continuous negative pressure was also applied (100 mmHg; Fig. 2). Subsequently, VAC treatment was repeated every $72 \mathrm{~h} 7$ time in total. Excellent wound healing was achieved, and the orocutaneous fistula was successfully closed without a surgical procedure (Fig. 3). The patient has been followed up for 2 years and 2 months, and there has been no evidence of a recurrent infection.

\section{Discussion}

Orocutaneous fistulas tend to occur after extensive resections and are performed for locally advanced tumours of the oral cavity with a reported incidence of $70 \%$. In general, mandibular plate exposure occurs in about $45 \%$ of cases, while no standard treatment is performed (1). Particularly in cases of plate infection and exposure, it is necessary to remove the mandibular reconstruction plate to achieve complete recovery. However, there are some disadvantages such as prolonged hospitalization and delayed adjuvant therapy, which can result in a decreased quality of life or vascular rupture. Unfortunately, there is no standardised method of treatment. The management of orocutaneous fistulas is usually determined by their size and location, and the direction of salivary flow $(2,3)$. The VAC system was recently introduced for managing complicated wounds (4), and it is widely used to treat fistulas (5-7). The VAC system has been used on wounds of nearly every aspect of the body but not routinely in the head and neck area such as cancer, trauma and infections. Satteson et al (8), reported the usefulness of VAC system in the treatment of complex head and neck wounds. They reported that wounds healed without complication in $44 \%$ of the skin grafts, $67 \%$ of Integra-covered wounds, and $71 \%$ of debrided wounds. The usefulness of VAC system for orocutaneous fistula have already reported (9-11). Our case report was the first report as a conservative therapy with a postoperative orocutaneous fistula and exposed mandibular plate with only the VAC system. The VAC system also increases the rate of tissue granulation, augments wound contracture and decreases bacterial load on a wound (12). In addition, the VAC system promotes fibroblast stimulation and accelerates removal of excessive fluid from wound (13). 


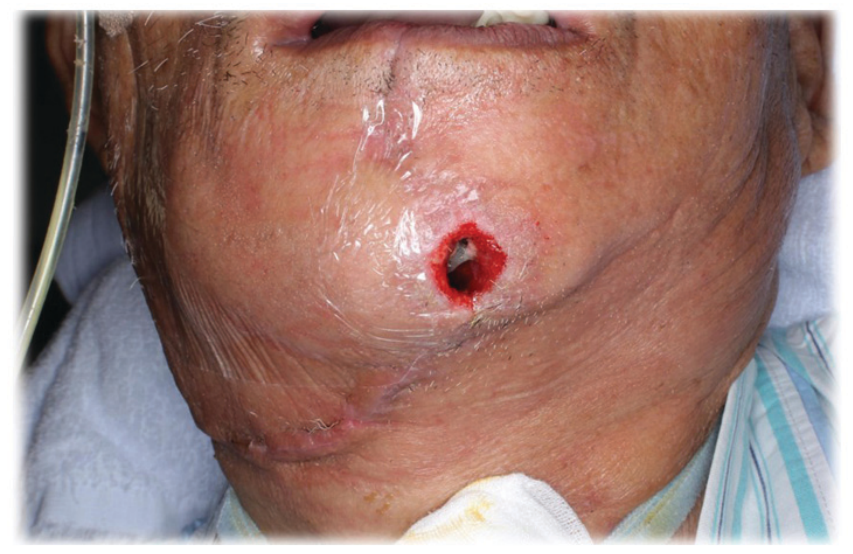

Figure 1. Orocutaneous fistula with mandibular plate exposure.

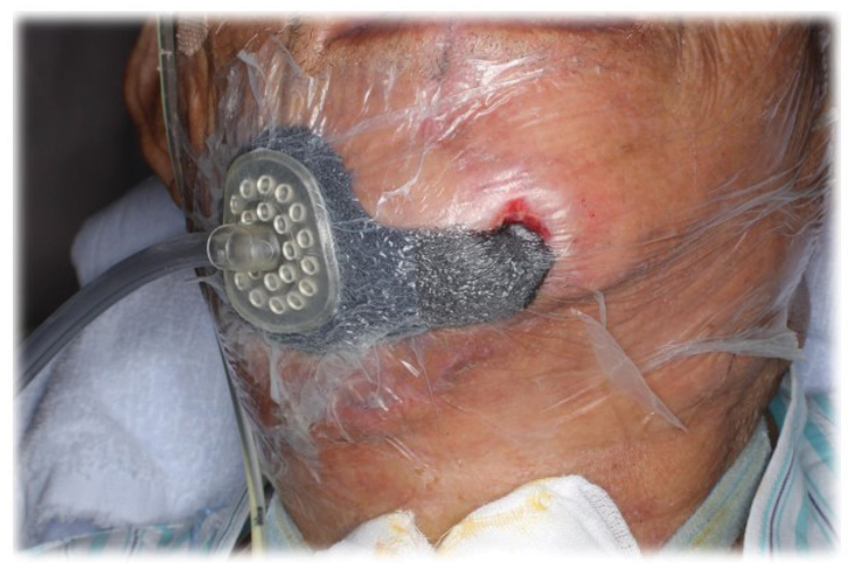

Figure 2. Following debridement, the vacuum-assisted closure system was applied to the orocutaneous fistula.

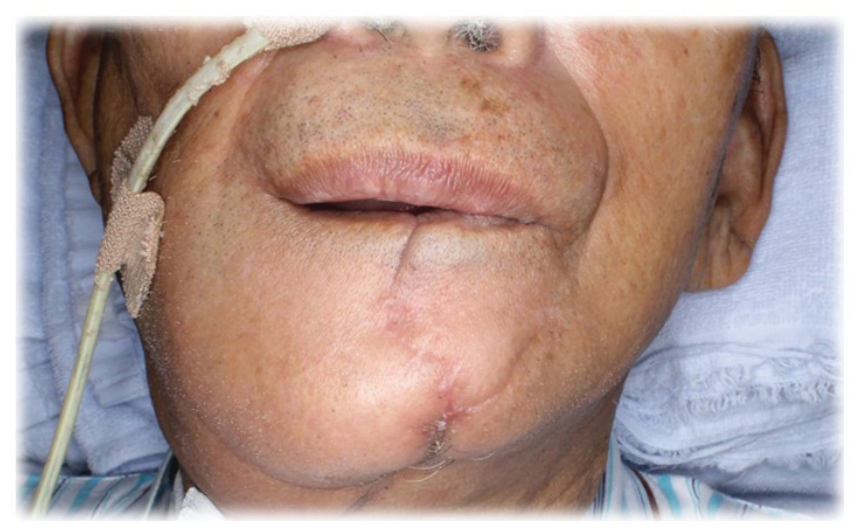

Figure 3. The surface of the skin after the orocutaneous fistula was successfully closed.

In our case, we treated postoperative orocutaneous fistula and exposed mandibular plate with the VAC system. During treatment, the VAC system can save the medical staff time since frequent dressings are unnecessary. Moreover, since VAC is repeated only every $72 \mathrm{~h}$, it facilitates wound care. In our case, there were no complications associated with the VAC system. This is a cost-effective and safe treatment for patients and hospital staff. In fact, there is however some costing research in other patient populations, with one study of patients with diabetic foot wounds finding that the average cost to achieve healing was less in the VAC group (14). We strongly recommend treating orocutaneous fistula with the VAC system in the future.

\section{Acknowledgements}

Not applicable.

\section{Funding}

No funding was received.

\section{Availability of data and methods}

The data generated during the present study are available from the corresponding author on reasonable request.

\section{Authors' contributions}

HG, TH and KN made substantial contributions to the design of the VAC therapy, analysis of the clinical data of the work, drafting the manuscript and revising it critically for important intellectual content. All authors gave their final approval of the version to be published and agree to be accountable for all aspects of this work in ensuring that questions related to the accuracy.

\section{Ethics approval and consent to participate}

Not applicable.

\section{Patient consent for publication}

The patient provided consent for publication.

\section{Competing interests}

The authors declare that they have no competing interests.

\section{References}

1. EI-Zohairy MA,Mostafa A,Amin A,Abd El-Fattah H and Khalifa S: Mandibular reconstruction using pectoralis major myocutaneous flap and titanium plates after ablative surgery for locally advanced tumors of the oral cavity. J Egypt Natl Canc Inst 21: 299-307, 2009.

2. Raman R and Ariayanayagam C: Closure of orocutaneous and pharyngocutaneous fistulas. Plast Reconstr Surg 79: 310, 1987.

3. Cohen M, Marschall MA and Greager J III: Early, aggressive management of postoperative oropharyngocutaneous fistulas. Plast Reconstr Surg 89: 56-61, 1992

4. Argenta LC and Morykwas MJ: Vacuum-assisted closure: A new method for wound control and treatment: Clinical experience. Ann Plast Surg 38: 563-577, 1997.

5. Walma MS, Burbach JP, Verheijen PM, Pronk A and van Grevenstein WM: Vacuum-assisted closure therapy for infected perineal wounds after abdominoperineal resection. A retrospective cohort study. Int J Surg 26: 18-24, 2016.

6. Perentes JY, Abdelnour-Berchtold E, Blatter J, Lovis A, Ris HB, Krueger T and Gonzalez M: Vacuum-assisted closure device for the management of infected postpneumonectomy chest cavities. J Thorac Cardiovasc Surg 149: 745-750, 2015.

7. Tavusbay C, Genc H, Clin N, Kar H, Kamer E, Atahan K and Haciyanli M: Use of a vacuum-assisted closure system for the management of enteroatmospheric fistulae. Surg Today 45: 1102-1111, 2015. 
8. Satteson ES, Crantford JC, Wood J and David LR: Outcomes of vacuum-assisted therapy in the treatment of head and neck wounds. J Craniofac Surg 26: e599-e602, 2015.

9. Andrews BT, Smith RB, Hoffman HT and Funk GF: Orocutaneous and pharyngocutaneous fistula closure using a vacuum-assisted closure system. Ann Otol Rhinol Laryngol 117: 298-302, 2008.

10. Tian B, Khoo D, Tay AC, Soo KC, Tan NC, Tan HK and Iyer NG: Management of orocutaneous fistulas using a vacuum-assisted closure system. Head Neck 36: 873-881, 2014.

11. Tian B, Iyer NG, Tan HK, Tay AC, Soo KC and Tan NC: Novel technique of creating a seal for the vacuum-assisted closure system application in complex head and neck wounds. Head Neck 38: E2523-E2526, 2016.
12. Morykwas MJ, Argenta LC, Shelton-Brown EI and McGuirt W: Vacuum-assisted closure: A new method for wound control and treatment: Animal studies and basic foundation. Ann Plast Surg 38: 553-562, 1997.

13. Venturi ML, Attinger CE, Mesbahi AN, Hess CL and Graw KS: Mechanisms and clinical applications of the vacuum-assisted closure (VAC) Device: A review. Am J Clin Dermatol 6: 185-194, 2005.

14. Apelqvist J, Armstrong DG, Lavery LA and Boulton AJ: Resource utilization and economic costs of care based on a randomized trial of vacuum-assisted closure therapy in the treatment of diabetic foot wound. Am J Surg 195: 782-788, 2008. 